\title{
Elevated factor VIII levels and arterial stroke: a review of literature with a case report
}

\author{
Dinesh Khandelwal ${ }^{1}$, Vaibhav Mathur ${ }^{1,2^{*}}$, Arvind Vyas ${ }^{1}$, Chandani Shah ${ }^{1}$, Chandrajeet Singh Ranawat ${ }^{1}$ and \\ Parth Patel ${ }^{1}$
}

\begin{abstract}
Background: Cerebral arterial thromboses or ischemic strokes may be caused by cumulative or independent effects of a variety of risk factors. High factor VIII level is one of those important but less known risk factors for arterial and venous thrombosis. We hereby provide a comprehensive review of the role of high factor VIII levels as a risk factor of arterial thrombosis. Moreover, we present our views on inclusion of factor VIII testing in the etiology workup protocol of young patients with ischemic strokes and their treatment with anticoagulant therapy.

Case presentation: We illustrate a case of 32-year-old North Indian female patient with Ischemic stroke whose only identifiable risk factor was revealed to be an elevated factor VIII level. She was treated with oral anticoagulant with an uneventful follow-up of 6 months.

Conclusions: Elevated factor VIII levels have their independent and additive effects in causation and prognosis of arterial strokes. We herein discuss the mechanism of this association, the feasibility and yield of routine testing, appropriate cut-off levels, and further treatment protocol especially in young stroke patients.
\end{abstract}

Keywords: Factor VIII, Stroke, Thrombophilia, Young, Case report

\section{Background}

In urban India, stroke is responsible for $1 \%$ mortality among total hospital admissions, and around $20 \%$ of all central nervous system disorders. Moreover, the underlying cause of stoke remains elusive in as many as $30 \%$ of cases [1]. An investigation panel comprising uncommon risk factors like factor VIII levels might disclose the mystery, especially in young stroke patients without traditional risk factors. However, till date, Indian literature is quite scanty on this association of factor VIII with ischemic strokes, with no major published articles addressing this causal association. Besides many unanswered issues pertaining the reason and significance of raised factor VIII levels, their independent and additive effects causing a pro-coagulant state, the feasibility

\footnotetext{
*Correspondence: drmathurvbhv@gmail.com

${ }^{1}$ Department of Neurology, SMS Medical College, Jaipur, Rajasthan, India

${ }^{2}$ Jaipur, India
}

\section{Springer Open}

(c) The Author(s). 2021 Open Access This article is licensed under a Creative Commons Attribution 4.0 International License, which permits use, sharing, adaptation, distribution and reproduction in any medium or format, as long as you give appropriate credit to the original author(s) and the source, provide a link to the Creative Commons licence, and indicate if changes were made. The images or other third party material in this article are included in the article's Creative Commons licence, unless indicated otherwise in a credit line to the material. If material is not included in the article's Creative Commons licence and your intended use is not permitted by statutory regulation or exceeds the permitted use, you will need to obtain permission directly from the copyright holder. To view a copy of this licence, visit http://creativecommons.org/licenses/by/4.0/. treatment are being discussed in this article along with a case example.

Thrombotic disorders are classified broadly as arterial thrombosis and venous thrombosis, the most basic distinction being that arterial thrombi are platelet-rich while venous thrombi are fibrin-rich thrombi (Fig. 1) [2]. Most prototypic examples of arterial thrombosis are ischemic heart disease (IHD) and ischemic stroke (IS), and those of venous thromboses are deep vein thrombosis and pulmonary embolism respectively. However, increasing evidence favors some degree of overlap in the pathogenesis of these two conditions [3].

Regarding arterial strokes, the well-established risk factors include smoking, hypertension, hyperlipidemia, obesity, diabetes, and a positive family history $[4,5]$. 


\section{Major differences between arterial and venous thrombosis}

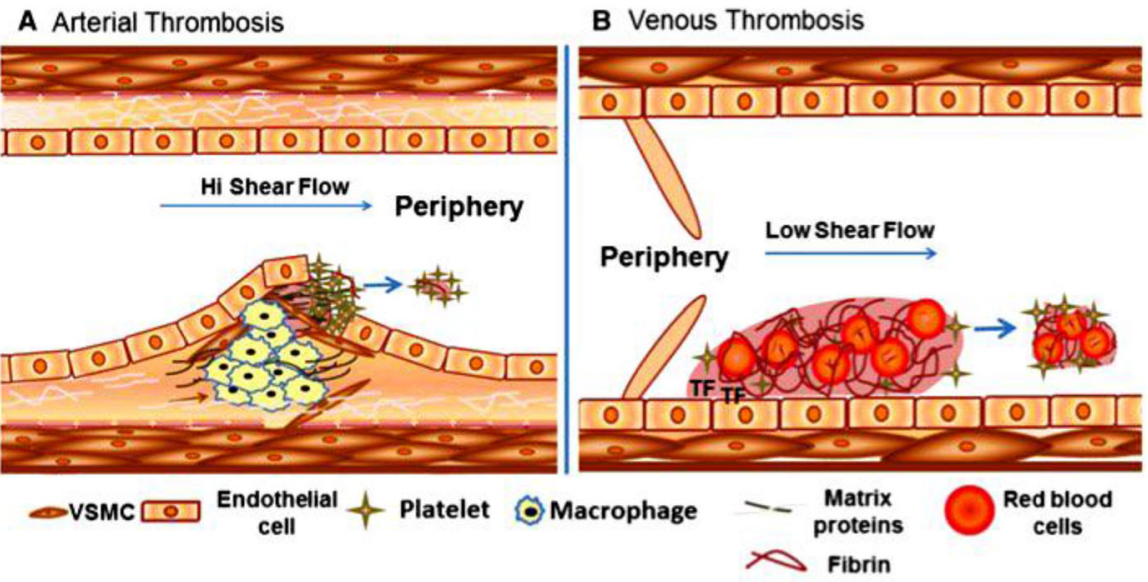

(A) Arterial thrombosis occurs under high shear flow when platelet rich thrombi are formed around ruptured atherosclerotic plaques and damaged endothelium. (B) Venous thrombosis occurs under low shear flow and mostly around intact endothelia wall. Venous thrombi are fibrin rich, encapsulating a large amount of red blood cells in addition to activated platelets.

Fig. 1 Arterial and Venous thrombi [2]

\section{Factor VIII levels and arterial thrombosis}

Besides the traditional risk factors, some individuals are genetically predisposed to thrombotic events and are commonly referred to as having inherited thrombophilia or a hypercoagulable state [6]. This entity includes genetic variants (Table 1) [3] that alter the production, activity, or metabolism of specific coagulation factors which can affect hemostasis and coagulation and predispose the mutation carriers to atherothrombotic or thromboembolic events. Variations in levels of factor VII and fibrinogen have been previously associated with arterial thrombotic disorders [7].

However, various genome-wide association studies (GWAS) later identified genetic loci linked with an increased risk of atherothrombotic disease [8]. Specifically, the cohorts for heart and aging research in genome epidemiology (CHARGE) GWAS identified altered factor VIII levels with genetic variants of the genes,

Table 1 Common genetic variants of coagulation factors in association with arterial thrombosis [3]

\begin{tabular}{|c|c|c|}
\hline Gene & Phenotype & Association \\
\hline F1341 & Increased factor XIII activation by thrombin & Protective effect for MI and IS. \\
\hline VWF, for example, Thr789Ala & High vWF levels & $\begin{array}{l}\text { Increased risk of atherothrombotic } \\
\text { disease. }\end{array}$ \\
\hline THBD, for example, Ala455Val, Ala25Thr & Decreased thrombomodulin levels & Increased risk of $\mathrm{Ml}$. \\
\hline CBS & $\begin{array}{l}\text { Deficiency of the enzyme cystathionine } \\
\text { B-synthase Ihomocystinurial }\end{array}$ & $\begin{array}{l}\text { Increased risk of atherosclerosis and } \\
\text { arterial thrombosis, including stroke. }\end{array}$ \\
\hline $\begin{array}{l}\text { F7, for example, Arg353Gln, the HVR4 } \\
\text { polymorphism, } 401 \mathrm{G} / \mathrm{T},-402 \mathrm{G} / \mathrm{A} \\
-59 \mathrm{~T} / \mathrm{G},-32 \mathrm{~A} / \mathrm{C}\end{array}$ & High levels of factor VII & Higher risk of death from CHD. \\
\hline $\begin{array}{l}\text { FGB, for example, Arg } 448 \mathrm{Lys}, \mathrm{Bcll} \text {, } \\
-148 \mathrm{C} / \mathrm{T},-455 \mathrm{G} / \mathrm{A} \text { (Haelli), and }-854 \mathrm{G} / \mathrm{A} \\
\text { polymorphisms }\end{array}$ & High levels of fibrinogen & $\begin{array}{l}\text { Increased risk of death from } \mathrm{CHD} \text {. } \\
\text { Increased risk of } \mathrm{MI}, 1 \mathrm{~S} \text {, and peripheral } \\
\text { vascular disease. }\end{array}$ \\
\hline PIA, for example, Leu33Pro & Lower levels of glycoprotein IIIA & Reduced risk of arterial thrombosis. \\
\hline
\end{tabular}

CHD coronary heart disease, IS ischemic stroke, MI myocardial infarction, vWF von Willebrand factor 
STXBP5, SCARA5, and STAB2 in 23,000 European participants [9].

Factor VIII (FVIII) is a plasma sialoglycoprotein, a $\beta 2$ globulin, consisting of 6 subunits (A1-A2-B-A3-C1-C2) and 2 chains (light chain and heavy chain), and is produced in the liver, spleen, and lymph nodes. Factor VIII circulates with von Willebrand factor (vWF) in plasma in an inactive form and has an essential role in normal coagulation pathway. On activation, it acts on platelet membranes triggering a series of downstream reactions that lead to formation of fibrin and a thrombus. More popularly known to cause hemophilia in a deficient state, FVIII in elevated serum levels, on the contrary, was later found to be a thrombophilia state. The Leiden thrombophilia study was the first to report that factor VIII is a risk factor for venous thromboembolism [10, 11]. Later on, its association was also found with an increased risk of coronary artery disease and peripheral arterial thrombosis [12]. Independent association between high FVIII levels and an increased risk of ischemic stroke was then revealed [13], and furthermore, combined elevations of FVIII and vWF in patients of acute ischemic stroke were found to be related to worse neurologic outcome, inpatient complications, recurrence [14], and even unfavorable outcomes post-thrombolysis [15].

The likely mechanisms for this increased thrombogenicity associated with elevated plasma FVIII are:

a) Direct positive influence on thrombin generation (i.e., reduced lag time, increased peak thrombin formation, and increased endogenous thrombin potential) [16]

b) Diminishing the influence of the anticoagulant pathway (e.g., a direct inverse relationship between plasma FVIII:C levels and activated protein $\mathrm{C}$ resistance) [17]

c) Acts as a potentiating risk factor in presence of other thrombophilic states (e.g., in women on oral contraceptive pills [18], pre-existing malignancy [19], factor V Leiden mutation [20])

\section{Determinants of factor VIII levels}

FVIII circulates in the plasma with vWF, which inhibits its proteolytic degradation, forming a stable complex. The crucial determinants of plasma FVIII levels being vWF levels and the $\mathrm{ABO}$ blood group, both being independent predictors of factor VIII half-life as well [21].

Under physiological conditions, vWF binds nearly $94 \%$ of FVIII molecules, preventing their degradation and maintaining the half-life, while the rest $6 \%$ circulates in free-form [22]. In case plasma vWF is low, the half-life of free FVIII is markedly reduced. Thus, plasma vWF plays a critical role in regulating plasma FVIII levels. Interestingly, patients with history of venous thrombosis had associated elevated FVIII:C levels and the proportion of free FVIII in the plasma are reduced. Consequently the FVIII:vWF ratio is also significantly increased in this cohort of patients [22].

The blood levels of the FVIII-vWF complex are also influenced by $\mathrm{ABO}$ blood group. Individuals with blood group O have 25-30\% lower plasma vWF:Ag (von Willebrand factor antigen) and FVIII:C (levels as compared to non- $\mathrm{O}$ individuals). In descending order, $\mathrm{AB}$ individuals have the highest plasma vWFAg levels, followed by group B, group A, and group O [23]. This blood group effect is likely due to differential in vivo clearance of vWF.

However, vWF:Ag and ABO blood group are risk factors for thrombosis only by virtue of their influence on plasma FVIII:C levels and not independently. Other factors associated with increased plasma levels of the FVIIIvWF complex include increasing age, sex (women higher than men), exercise, stress, pregnancy, surgery, acute phase response (e.g., chronic inflammation or malignancy), hypertension, hyperlipidemia, obesity, diabetes, and hyperthyroidism [3].

As in our patient, normal pregnancy can be associated with elevated plasma levels of FVIII:C; however, it is not linked with poor pregnancy outcome. Furthermore, post-puerperal period shows a distinct decrease of FVIII levels. Hence, in cases of an outlasting elevation of the FVIII, there arises is a necessity to rule out thrombophilia [24].

\section{Practicality of routine factor VIII level testing and further treatment}

Given the aforementioned strong independent associations between high factor VIII levels and the risk of arterial thrombosis, should we routinely investigate for elevated factor VIII levels in patients with atherothrombotic disease?

If yes, what should be the timing of sample collection and the type of FVIII assay to be used?

How should we interpret the cut-off values given the inter-individual variations, ethnic variations, and the impact of environmental factors on plasma Factor VIII levels?

And finally, what should be the adequate anticoagulant treatment duration for prevention of recurrences?

Firstly, there is no present consensus on testing of blood FVIII levels in patients with atherothrombotic disease; however with increasing published evidences of this association, further studies addressing this issue are essential. Regarding the timing of measurement of factor VIII levels, standard laboratory guidelines propose that factor VIII measurement should be postponed for 4-6 weeks after the discontinuation of anticoagulant and thrombolytic therapies [25], for 6 weeks postpartum, 
and for at least 6 months after an acute thrombotic event. Also, the tests need to be repeated after 3-6 months for confirmation [26]. For laboratory testing, assays employed for measuring plasma FVIII levels can be determined in a functional clotting assay (FVIII:C), in a chromogenic assay (FVIII:Ch), or via a standard enzyme-linked immunosorbent assay methodology for factor VIII-related antigen (FVIII:Ag). However, if FVIII levels are to be included in the thrombophilia screen, it seems reasonable that the FVIII:C assay (factor VIII functional clotting assay) is utilized. Decision regarding a uniform upper limit for FVIII levels is another tedious task. In most parts of the world, a level of $>150 \mathrm{IU} / \mathrm{dl}$ is considered abnormal [27]. However, variations with age (increase of $5 \mathrm{IU} / \mathrm{dL}$ with each decade), sex (higher in females), pregnancy, race (higher levels in AfricanAmericans than in Caucasians), blood group (non-O more than $\mathrm{O}$ ), and genetic factors affecting vWF levels (not FVIII levels directly) make it difficult to consider a single cut-off value for all. Moreover, plasma FVIII:C levels constitute a dose-dependent risk factor for thrombosis, and also as a potentiating factor in those with other prothrombotic states [11].

Finally, regarding the appropriate treatment for patients with elevated factor VIII levels and atherothrombotic disease, there is little consensus for patients who have suffered their first arterial thrombotic event, and anticoagulant therapy needs to be weighed between the risk of recurrence and potential bleeding complications. One small prospective study [28] suggested that extended duration anticoagulant therapy (30 months rather than 6 months) was effective in reducing the risk of recurrence. However, we still await conclusive randomized trials for definitive guidelines for the same.

\section{Case presentation}

A 32-year-old female suffered sudden onset weakness of her left hand in form of difficulty gripping objects and difficulty buttoning unbuttoning with her left hand 6 months back. She was 8 months pregnant at the time of event, had left handgrip weakness on examination, and was advised magnetic resonance imaging brain, which revealed a right parietal infarct (Fig. 2). Relevant detailed history was taken for any pre-existing heart disease, smoking, previous blood transfusions, joint pains, previous abortions, chronic headache, and fever which were all negative. Patient was started on low dose aspirin orally and had gradual improvement in her weakness with physiotherapy. However, an extensive workup for young stroke was done, including blood counts, sickling test, routine and Holter electrocardiography, echocardiography (transthoracic and transesophageal), carotid and brain angiography, vasculitis profile, autoimmune profile, serum homocysteine, and anti-phospholipid antibody panel testing which were all found to be normal. Given the known effects of pregnancy on serum levels of clotting factors, coagulation profile was planned postpartum. Rest of the pregnancy including delivery was uneventful. She underwent a detailed coagulation profile after 3 months and 6 months, both of which revealed significantly elevated levels $(274 \mathrm{IU} / \mathrm{dL})$ of factor VIII (Fig. 3). The "normal" upper cut-off value used for factor VIII was $150 \mathrm{IU} / \mathrm{dL}$. She was then started on oral anticoagulant, after her lactation period was over, in order to prevent development of new thromboses.

\section{Conclusion}

In conclusion, elevated FVIII levels do not simply reflect a post-thrombotic acute phase response; these rather play an important role in the pathogenesis of the thrombosis. Although the published data being primarily epidemiological, we can conclude that high factor VIII levels are an independent risk factor for thrombosis, having a greater impact on venous than on arterial thrombosis. Various genetic and environmental factors have been described known to alter FVIII levels, most noteworthy being the $\mathrm{ABO}$ blood group and vWF levels from the first category while old age, blacks, and women in the second category.

Studies have shown that FVIII levels appear to be associated with both occurrence as well as outcome of

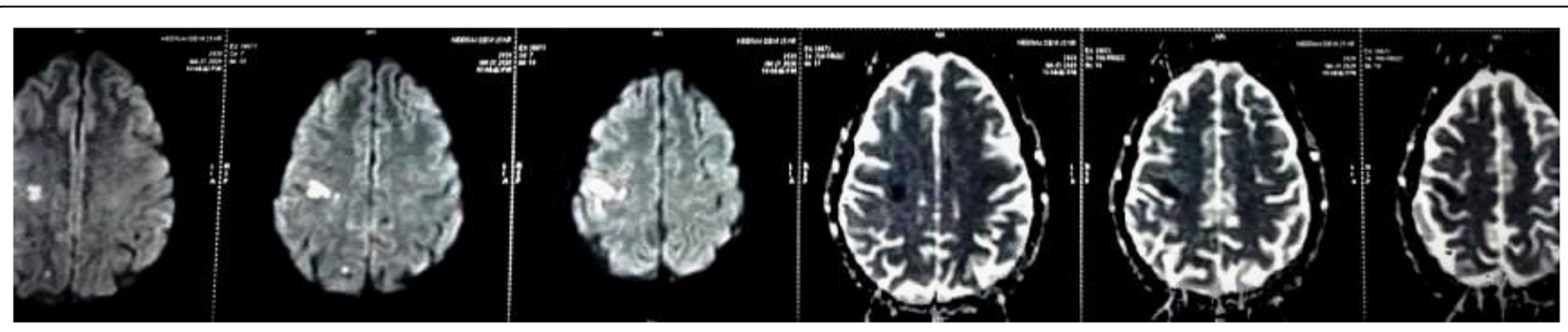

Fig. $2 \mathrm{MRI}$ brain diffusion weighted image showing right parietal infarct 


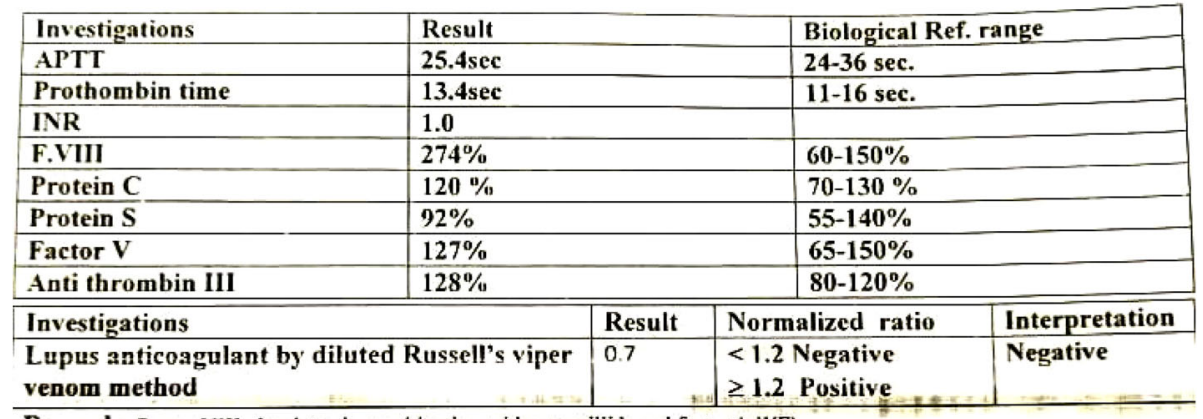

Remark: factor VIII circulates in combination with von willi brand factor (vWF)

$\begin{array}{lll}\text { Severe } & \text { Hemophilia } & <1 \% \\ \text { Moderate } & \text { Hemophilia } & 1-5 \% \\ \text { Mild } & \text { Hemophilia } & 6-30 \% \\ & \text { vWF } & 20-50\end{array}$

Fig. 3 The coagulation profile at 6 months post stroke

ischemic stroke such that asymptomatic adults with elevated FVIII levels have twice the risk of ischemic stroke as compared to those with normal or low FVIII [29]. However, despite not yet universally recommended as part of routine thrombophilia screening, its potential role in prognostication and association with arterial thrombotic events is undeniable.

As far as protocol of our institution is concerned, we have placed FVIII testing in a second tier set of investigations in all arterial thrombotic events including ischemic strokes, and in first tier set for venous thromboses. On basis of previous studies which described successful treatment of ischemic stroke patients and high FVIII levels with oral anticoagulant therapy, we also considered the same in our patient [2]. Nonetheless, further studies are essential in order to establish a treatment algorithm.

\section{Abbreviations}

IHD: Ischemic heart disease; IS: Ischemic stroke; GWAS: Genome-wide association studies; CHARGE: Cohorts for Heart and Aging Research in Genome Epidemiology; FVIII: Factor VIII; FVIII:Ag: Factor VIII-related antigen; FVIII:C: Factor VIII functional clotting assay; FVIII:Ch: Factor VIII chromogenic assay; vWF: Von Willebrand factor; VWF:Ag: Von Willebrand factor antigen

\section{Acknowledgements}

We acknowledge our sincere thanks to the institution, which provides us such a giant platform to work upon; our patients, whom we see and learn from; and our families and colleagues, who selflessly support our endeavors.

\section{Authors' contributions}

DK was the primary treating doctor; he first detected the peculiarity of the case, suggested for publication, planned the design, guided throughout, and reviewed the manuscript. VM collected the data, compiled it, and did the literature search along with $\mathrm{AV}$, and both were involved in manuscript preparation, editing, and review. CS, CSR, and PP helped in patient counseling, literature search, and manuscript preparation. All authors have read and approved the manuscript.
Funding

Institutional funding for in hospital investigations.

Availability of data and materials

Not applicable.

Ethics approval and consent to participate

Not applicable.

Consent for publication

Written informed consent was obtained from the patient for participation and publication of this brief communication and accompanying images.

\section{Competing interests}

None.

Received: 6 August 2020 Accepted: 18 January 2021

Published online: 05 February 2021

\section{References}

1. Lasek-Bal A, Puz P, Kazibutowska Z. Elevated factor VIII level and stroke in patients without traditional risk factors associated with cardiovascular diseases. Neuropsychiatr Dis Treat. 2013;9:847-52.

2. Koupenova M, Kehrel BE, Corkrey HA, Freedman JE. Thrombosis and platelets: an update. Eur Heart J. 2017;38(11):785-91.

3. Algahtani FH, Stuckey R. High factor VIII levels and arterial thrombosis: illustrative case and literature review. Ther Adv Hematol. 2019;10: 2040620719886685.

4. Yusuf S, Hawken S, Ounpuu S, Dans T, Avezum A, Lanas F, et al. Effect of potentially modifiable risk factors associated with myocardial infarction in 52 countries (the INTERHEART study): case-control study. Lancet. 2004; 364(9438):937-52.

5. Previtali E, Bucciarelli P, Passamonti SM, Martinelli I. Risk factors for venous and arterial thrombosis. Blood Transfus. 2011;9(2):120-38.

6. Mi Y, Yan S, Lu Y, Liang Y, Li C. Venous thromboembolism has the same risk factors as atherosclerosis: a PRISMA-compliant systemic review and metaanalysis. Medicine (Baltimore). 2016;95(32):e4495.

7. Voetsch B, Loscalzo J. Genetic determinants of arterial thrombosis. Arterioscler Thromb Vasc Biol. 2004:24(2):216-29.

8. Lotta LA. Genome-wide association studies in atherothrombosis. Eur J Intern Med. 2010;21(2):74-8.

9. Smith NL, Chen MH, Dehghan A, Strachan DP, Basu S, Soranzo N, et al. Novel associations of multiple genetic loci with plasma levels of factor VII, factor VIII, and von Willebrand factor: The CHARGE (Cohorts for Heart and 
Aging Research in Genome Epidemiology) Consortium. Circulation. 2010; 121(12):1382-92.

10. Koster T, Blann AD, Briët E, Vandenbroucke JP, Rosendaal FR. Role of clotting factor VIII in effect of von Willebrand factor on occurrence of deep-vein thrombosis. Lancet. 1995;345(8943):152-5.

11. Jenkins PV, Rawley O, Smith OP, O'Donnell JS. Elevated factor VIII levels and risk of venous thrombosis. Br J Haematol. 2012;157(6):653-63.

12. Bank I, Libourel EJ, Middeldorp S, Hamulyák K, van Pampus EC, Koopman MM, et al. Elevated levels of FVIII:C within families are associated with an increased risk for venous and arterial thrombosis. J Thromb Haemost. 2005; 3(1):79-84.

13. Kuo CY, Lin CH, Kuo YW, Huang YC, Hsu HL, Lin YH, et al. Factor VIII levels are associated with ischemic stroke, stroke subtypes and neurological worsening. Curr Neurovasc Res. 2015;12(1):85-90.

14. Samai A, Monlezun D, Shaban A, George A, Dowell L, Kruse-Jarres R, et al. Von Willebrand factor drives the association between elevated factor VIII and poor outcomes in patients with ischemic stroke. Stroke. 2014;45(9): 2789-91.

15. Tóth NK, Székely EG, Czuriga-Kovács KR, Sarkady F, Nagy O, Lánczi LI, et al. Elevated factor VIII and von Willebrand factor levels predict unfavorable outcome in stroke patients treated with intravenous thrombolysis. Front Neurol. 2018;8:721.

16. Machlus KR, Colby EA, Wu JR, Koch GG, Key NS, Wolberg AS. Effects of tissue factor, thrombomodulin and elevated clotting factor levels on thrombin generation in the calibrated automated thrombogram. Thromb Haemost. 2009;102(5):936-44.

17. Laffan MA, Manning R. The influence of factor VIII on measurement of activated protein C resistance. Blood Coagul Fibrinolysis. 1996;7(8):761-5.

18. Legnani C, Cini M, Cosmi B, Poggi M, Boggian O, Palareti G. Risk of deep vein thrombosis: interaction between oral contraceptives and high factor VIII levels. Haematologica. 2004;89(11):1347-51.

19. Kamphuisen PW, Rosendaal FR, Eikenboom JC, Bos R, Bertina RM. Factor V antigen levels and venous thrombosis: risk profile, interaction with factor $V$ leiden, and relation with factor VIII antigen levels. Arterioscler Thromb Vasc Biol. 2000;20(5):1382-6.

20. Vormittag R, Simanek R, Ay C, Dunkler D, Quehenberger P, Marosi C, et al. High factor VIII levels independently predict venous thromboembolism in cancer patients: the cancer and thrombosis study. Arterioscler Thromb Vasc Biol. 2009;29(12):2176-81.

21. Kamphuisen PW, Houwing-Duistermaat JJ, van Houwelingen $\mathrm{HC}$, et al. Familial clustering of factor VIII and von Willebrand factor levels. Thromb Haemost. 1998;79:323-7.

22. Schambeck CM, Grossmann R, Zonnur S, Berger M, Teuchert K, Spahn A, Walter U. High factor VIII (FVIII) levels in venous thromboembolism: role of unbound FVIII. Thromb Haemost. 2004;92(1):42-6.

23. Jenkins PV, O'Donnell JS. ABO blood group determines plasma von Willebrand factor levels: a biologic function after all? Transfusion. 2006; 46(10):1836-44.

24. Procházka M, Procházková J, Lubuský M, Krcová V, Slavík L, Hrachovec P, Zielina P. Hladina faktoru VIII v casném poporodním období [Coagulation factor VIII in the early postpartum period]. Ceska Gynekol. 2005;70(2):138-43.

25. Heit JA. Thrombophilia: common questions on laboratory assessment and management. Hematol Am Soc Hematol Educ Program. 2007;2007:127-35.

26. Nakashima MO, Rogers HJ. Hypercoagulable states: an algorithmic approach to laboratory testing and update on monitoring of direct oral anticoagulants. Blood Res. 2014;49(2):85-94.

27. Goldenberg NA, Knapp-Clevenger R. Manco-Johnson MJ; Mountain States Regional Thrombophilia Group. Elevated plasma factor VIII and D-dimer levels as predictors of poor outcomes of thrombosis in children. $\mathrm{N} \mathrm{Engl} \mathrm{J}$ Med. 2004;351(11):1081-8.

28. Eischer L, Gartner V, Schulman S, Kyrle PA, Eichinger S. AUREC-FVIII investigators. 6 versus 30 months anticoagulation for recurrent venous thrombosis in patients with high factor VIII. Ann Hematol. 2009:88(5):485-90,

29. Siegler JE, Samai A, Albright KC, Boehme AK, Martin-Schild S. Factoring in Factor VIII With Acute Ischemic Stroke. Clin Appl Thromb Hemost. 2015; 21(7):597-602.

\section{Publisher's Note}

Springer Nature remains neutral with regard to jurisdictional claims in published maps and institutional affiliations.

\section{Submit your manuscript to a SpringerOpen ${ }^{\circ}$ journal and benefit from:}

- Convenient online submission

- Rigorous peer review

- Open access: articles freely available online

High visibility within the field

- Retaining the copyright to your article

Submit your next manuscript at $\boldsymbol{\nabla}$ springeropen.com 